\title{
Gamma-heavy chain disease
}

INSERM

\section{Source}

INSERM. (1999). Orphanet: an online rare disease and orphan drug data base. Gammaheavy chain disease. ORPHA:100026

Gamma-heavy chain disease (gamma-HCD) is a type of HCD (see this term) characterized by the production of incomplete monoclonal gamma-heavy chains without associated light chains. The clinical presentation most commonly resembles that of patients with systemic lymphoproliferative/autoimmune diseases. 